\title{
Temporal and spatial regulation of Rho-type guanine-nucleotide exchange factors: the yeast perspective
}

\author{
Marie-Pierre Gulli and Matthias Peter ${ }^{1}$ \\ Swiss Institute for Experimental Cancer Research (ISREC), 1066 Epalinges/VD, Switzerland
}

Cell polarity is involved in almost every aspect of cell and developmental biology and is functionally important for differentiation, proliferation, and morphogenesis in single-cell as well as multicellular organisms (Drubin 2000). Establishment of cell polarity is a multistep process that is regulated by internal cues or extracellular signals. It requires the selection of a specific site at the cell cortex ("landmark") followed by the recruitment and activation of components involved in actin or microtubule polymerization at that site. These cytoskeletal rearrangements lead to various forms of polarized growth, including asymmetric cell division, phagocytosis, the formation of filopodia, lamellipodia or stress fibers, and in the most extreme cases, the formation of axons and dentrites. Sustained polar growth further requires the stabilization of the polarization machinery at the cortex to maintain cytoskeletal polarization and targeting of secretion vesicles toward that region. Finally, the polarization machinery must be disassembled and/or inactivated to end the polar growth phase.

Actin rearrangements are regulated by small GTPases of the Rho and Ras subfamilies (Hall 1998), which are activated by a variety of growth factors, cytokines, and adhesion molecules. GTPases function as molecular switches, being inactive when bound to GDP and active when bound to GTP. Exchange of GTP for GDP induces a conformational change, which allows the effector domain to interact with downstream effectors. Many targets of Rho-GTPases have been identified, which together regulate the dynamic changes of the actin cytoskeleton in response to various intra- and extracellular signals. Several recent reviews have summarized and discussed the function of these downstream effectors in regulating the various stages of actin dynamics /Van Aelst and D'Souza-Schorey 1997; Aspenstrom 1999; Johnson 1999; Kaibuchi et al. 1999). However, much less is known about the regulation of the GTPases themselves. This is a challenging task, as Rho-type GTPases need to be controlled both temporally and spatially. For

${ }^{1}$ Corresponding author.

E-MAIL matthias.peter@isrec.unil.ch; FAX 41-21-652-6933.

Article and publication are at www.genesdev.org/cgi/doi/10.1101/ gad.876901. example, in a migrating cell, the same GTPase that is activated at the leading edge must be turned off at the trailing edge. The aim of this review is to highlight recent advances and emerging concepts describing the spatial and temporal regulation of guanine-nucleotide exchange factors (GEFs), the key regulators of Rho-type GTPases.

\section{Known regulators of GTPases}

Biochemical and genetic studies have led to the identification of three classes of regulatory proteins that control the nucleotide state of Rho family proteins. These are the guanine-nucleotide exchange factors (GEFs), the GTPase activating proteins (GAPs), and the guaninenucleotide dissociation inhibitors (GDIs; Fig. 1). In addition, Rho-GTPases are isoprenylated at their C termini by specific geranyl-geranyl- (GGTases) or farnesyl-transferases (FTases), and this lipid modification may target them to membrane microdomains. Rho-GTPases form an inactive cytosolic complex with GDIs, in which the GDI masks the C-terminal isoprenyl group and thereby prevents membrane association of the GTPase. This complex is in equilibrium with the membrane-bound form of the GTPase. GDIs preferentially bind to the GDP-bound form and prevent nucleotide release, thereby maintaining the GTPases in the inactive state. At the membrane, exchange of nucleotide is stimulated by GEFs, which catalyze the exchange of GTP for GDP by facilitating the release of GDP and transiently stabilizing the nucleotide-free form of the GTPase. Cellular GTP is present in $\sim 10$-fold molar excess over GDP, and binding of GTP stimulates the release of the activated GTPase from the GEF. The level of Rho-GTP can also be regulated by altering the activity of GAPs, which increase the intrinsic GTPase activity, thus favoring the conversion from the GTP- to the GDP-bound form.

In principle, local activation of GTPases in response to intra- or extracellular signals could occur by local activation of GEFs or inhibition of GAPs and/or GDIs. These different possibilities are not mutually exclusive, and it is likely that full activation of Rho-GTPases requires activation of GEFs as well as inactivation of their GAPs and/or GDIs. For example, the ERM proteins (ezrin, 


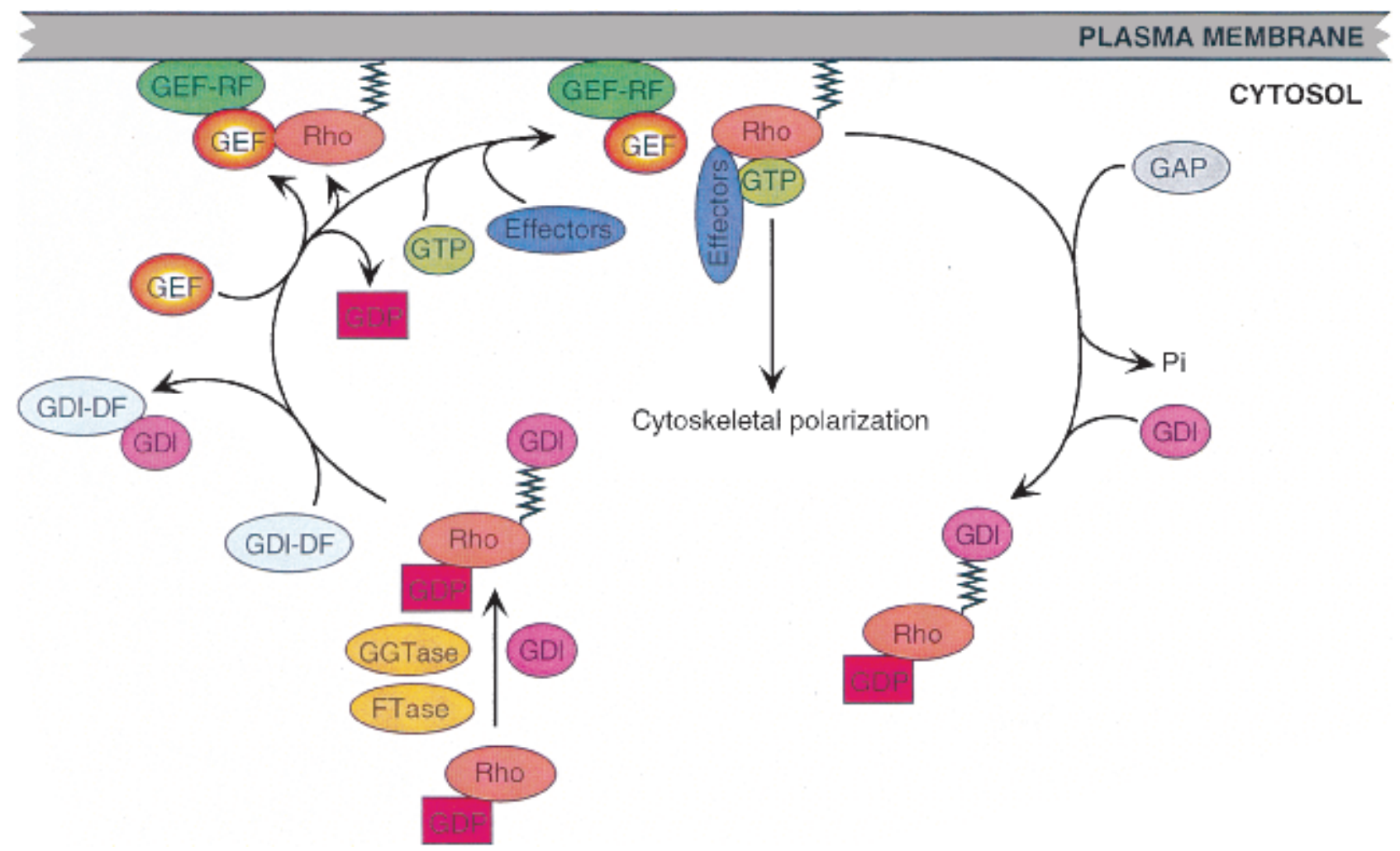

Figure 1. Mode of regulation of Rho-type GTPases. Rho-type GTPases (Rho) are isoprenylated at their C termini either by geranylgeranyl transferases (GGTases) or by farnesyl transferases (FTases). Through this lipid residue, GTPases can interact with membranes. Guanine-nucleotide dissociation inhibitors (GDIs) interact with the prenyl group of GDP-bound GTPases and keep them in the cytosol or prevent their transport to the membrane. GDI dissociation factors (GDI-DFs) such as the ERM proteins (ezrin, radixin, moesin) can bind to GDIs and reduce their activity, thereby facilitating GTPase activation. Guanine-nucleotide exchange factors (GEFs) are recruited to the plasma membrane by GEF-recruiting factors (GEF-RFs). GEFs then promote the release of GDP from the GTPases and transiently stabilize the GTPases in their nucleotide-free form. Binding of GTP releases the GTPases from the GEFs, allowing the GEFs to activate other GTPase molecules. GTP-bound GTPases bind to their effectors, which in turn, induce the appropriate cytoskeletal structures. By stimulating the intrinsic GTPase activity of the GTPases, GTPase activating proteins (GAPs) participate in the conversion of the GTPases to their inactive GDP-bound form to which GDIs can bind.

radixin, and moesin) have been shown to interact with Rho-GDI and inhibit its activity (Takahashi et al. 1997). Thus, the regulated release of compartmentalized GTPase may increase recruitment and activation at the plasma membrane, possibly as part of an amplification loop triggered by the GTPase itself. Recent studies in budding yeast strongly support a critical role for temporal and spatial regulation of Cdc24p, the GEF for Cdc42p, during cellular polarization in response to internal and extracellular cues. Below, we will summarize current knowledge of cell polarity and $\mathrm{Cdc} 42 \mathrm{p}$ regulation in yeast, and focus in particular on the regulation of its GEF Cdc24p. On the basis of the yeast model, we propose four separable steps that may be involved in the regulation of Rho-GEFs. In the last section of this review, we discuss a few selected examples to illustrate that these basic principles may be conserved in multicellular organisms.

\section{Cell polarity and polarized growth in yeast}

The yeast Saccharomyces cerevisiae exhibits polarized growth at several stages of its life cycle, making it an excellent model organism to study the biochemical pathways leading to rearrangements of the cytoskeleton. During vegetative growth, a bud forms late in the $G_{1}$ phase of the cell cycle (Pruyne and Bretscher 2000). The position on the cell cortex where bud growth will be initiated (incipient bud site) is not random but is regulated by several gene products in a cell-type dependent manner (Chant 1999). For example, the transmembrane protein Bud10p/Axl2p is required to guide the budding machinery to the correct position in haploid cells (Halme et al. 1996; Roemer et al. 1996), whereas Bud8p and Bud9p mark the site of polarization in diploid cells (Zahner et al. 1996). During mating, a pointed projection coined shmoo develops to allow contact and fusion with a cell of the opposite mating type. In this case, cell polarity is determined by a gradient of mating pheromones secreted by the mating partner (Arkowitz 1999; Bähler and Peter 2000). On nitrogen starvation, yeast cells elongate from one pole, forming chains of linked cells that spread across the substratum (Kron and Gow 1995; Roemer et al. 1996). All these asymmetric growth processes require polarized organization of the actin cytoskeleton. 
Central to the initiation of actin polarization is the local activation of the GTPase Cdc42p (Fig. 2A), and much will be learned if we understand when, where, and how Cdc42p is activated and inactivated. Regulation of Cdc42p involves its GEF Cdc24p, several putative GAPs (Bem2p, Bem3p, Rga1p, and Rga2p), the GDI Rdilp, and a subunit of the geranyl-geranyl transferase I Cdc43p, (Johnson 1999; Pruyne and Bretscher 2000). Whereas little is known about the regulation of Rdilp or the GAP molecules, much progress has been made in understanding the spatial and temporal regulation of Cdc24p. Cdc24p is the sole essential GEF for Cdc42p (Bi et al. 2000). As do all Rho-GEFs, it contains a domain with strong similarity to the Dbl-family of exchange factors (residues 283-452, Dbl-homology domain or DH) and a nearby pleckstrin-homology domain (residues 472-681, $\mathrm{PH})$. Cdc $24 \mathrm{p}$ also contains a calponin-homology $(\mathrm{CH})$ domain in its $\mathrm{N}$ terminus (residues 154-226), which in some proteins has been implicated in binding to actin (Stradal et al. 1998). Finally, Cdc24p has two calciumbinding domains (residues 649-658 and 820-831). Whereas the $\mathrm{PH}$ domain is thought to serve as a membrane-targeting signal (Bottomley et al. 1998), the func- tion of the $\mathrm{CH}$ - and calcium-binding motifs in regulation of Cdc $24 p$ is not clear.

Activation of Cdc $24 p$ is required during all stages of the yeast life cycle that involve polarized growth, but its role is best studied during the cell cycle and in response to mating pheromones. We will thus focus the following discussion on the regulation of $\mathrm{Cdc} 24 \mathrm{p}$ during these two stages.

\section{Recruitment and activation of $\mathrm{Cdc} 24 \mathrm{p}$ at bud emergence}

Cells in the early $G_{1}$ phase of the cell cycle grow isotropically until they reach a critical size, at which time activation of the cyclin-dependent kinase (CDK) Cdc28p-Clnp initiates actin polarization: Cortical actin patches congregate at the selected site, and actin cables become oriented along the mother-bud axis, resulting in polarized secretion and bud emergence (Lew and Reed 1995). The role of Cdc28p-Clnp in triggering cell polarization at bud emergence is not understood, but recent evidence suggests that it may be required for activating Cdc42p (Gulli et al. 2000). Surprisingly, Cdc24p is sequestered in the nucleus during the $G_{1}$ phase of the hap-
A

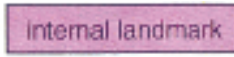

extracellular sigral-mediated landmark

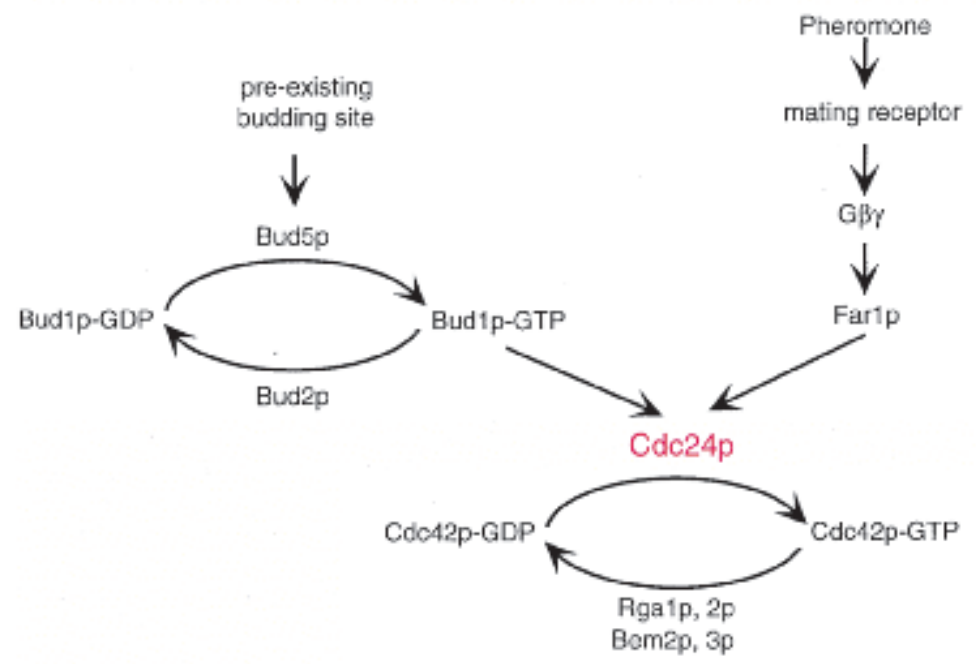

B
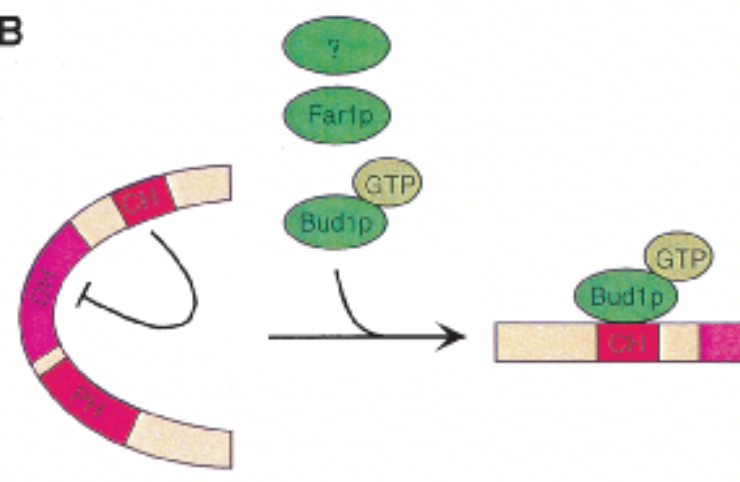

"Inactive" Cdc24p
"Active" Cdc24p
Figure 2. Mode of activation of Cdc24p, the yeast GEF for Cdc42p. (A) Upstream regulatory elements involved in $\mathrm{Cdc} 24 \mathrm{p}$ activation during budding and mating. Budding: The presence of Bud5p, the GEF for Rsrlp/Budlp at the preexisting budding site at the plasma membrane (internal landmark) allows local activation of Rsrlp/Budlp. Once bound to GTP, Rsrlp/ Budlp recruits and likely activates Cdc24p. Thus, Cdc42p-mediated actin polarization during budding involves a cascade of GTPases. Mating: Secreted pheromones bind to G-protein-coupled mating receptors. On receptor engagement, G $\alpha$ binds to GTP and dissociates from G $\beta \gamma$. Farlp targets $\mathrm{Cdc} 24 \mathrm{p}$ to $\mathrm{G} \beta \gamma$-activated receptor (extracellular signal-mediated landmark). In addition to bridging Cdc24p interaction to $G \beta \gamma$, Farlp may activate Cdc24p. (B) Proposed model for the activation of Cdc24p. In the absence of any activating signal, the $\mathrm{N}$-terminal calponin homology domain $(\mathrm{CH})$ may inhibit the catalytic Dbl homology domain (DH) of Cdc24p. Binding of the linker proteins Rsrlp/Budlp-GTP, Farlp, or as-yet-unidentified additional activators to the $\mathrm{CH}$ domain may open Cdc24p to its active conformation by removing the $\mathrm{N}$-terminal inhibitory domain, hence relieving the catalytic DH-domain. 
loid cell cycle by binding to the adapter Farlp (Toenjes et al. 1999; Nern and Arkowitz 2000b; Shimada et al. 2000). Cdc28p-Clnp phosphorylates Farlp at bud emergence, leading to ubiquitin-mediated degradation of Farlp (Henchoz et al. 1997) and subsequent release of Cdc24p from the nucleus (Fig. 3; Nern and Arkowitz 2000b; Shimada et al. 2000). However, phosphorylation of Farlp and release of Cdc24p are not the only functions of Cdc28pClnp at bud emergence, because cells expressing a cytoplasmic form of Cdc24p (Cdc24p-m1; Nern and Arkowitz 1998) still require Cdc28p-Clnp to induce cellular polarization. Indeed, Cdc28p-Clnp activity is necessary to recruit cytoplasmic Cdc $24 \mathrm{p}$ to the incipient bud site (Gulli et al. 2000). This membrane recruitment requires neither an intact actin cytoskeleton nor activated $\mathrm{Cdc} 42 \mathrm{p}$, indicating that Cdc28p-Clnp plays an as yet unidentified role at bud emergence (Gulli et al. 2000). Cdc28p-Clnp might phosphorylate Cdc24p, thereby inducing a change in its conformation that may allow its interaction with binding partners at the plasma membrane. Alternatively, Cdc28p-Clnp might phosphorylate components at the plasma membrane, which in turn, bind to Cdc24p.

Recent evidence suggests a crucial role for the small GTPase Rsr1p/Bud1p in the local activation of Cdc24p at bud emergence. Rsrlp/Bud1p was originally isolated as a multicopy suppressor of cdc24-4 mutant cells (Bender and Pringle 1989) and subsequently shown to bind directly to Cdc24p in a GTP-dependent manner (Park et al. 1997). Rsr1p/Bud1p is localized uniformly at the plasma membrane (Michelitch and Chant 1996), suggesting that its local activation may target Cdc24p to the incipient bud site. Indeed, Cdc24p localizes to random positions in rsr1/bud1s cells, and conversely, overexpressed Bud1pGTP uniformly recruits Cdc24p to the plasma membrane (Y. Shimada, P. Wiget, and M. Peter, unpubl.). Rsrlp/Bud1p is regulated by its GEF Bud5p and its GAP Bud2p, both of which localize to the incipient bud site (Park et al. 1999). Interestingly, Bud5p colocalizes with the transmembrane protein $\mathrm{Axl} 2 \mathrm{p} / \mathrm{Bud} 10 \mathrm{p}$, a component of the budding landmark, and directly interacts with its cytoplasmic tail (H.-O. Park, pers. comm.), suggesting

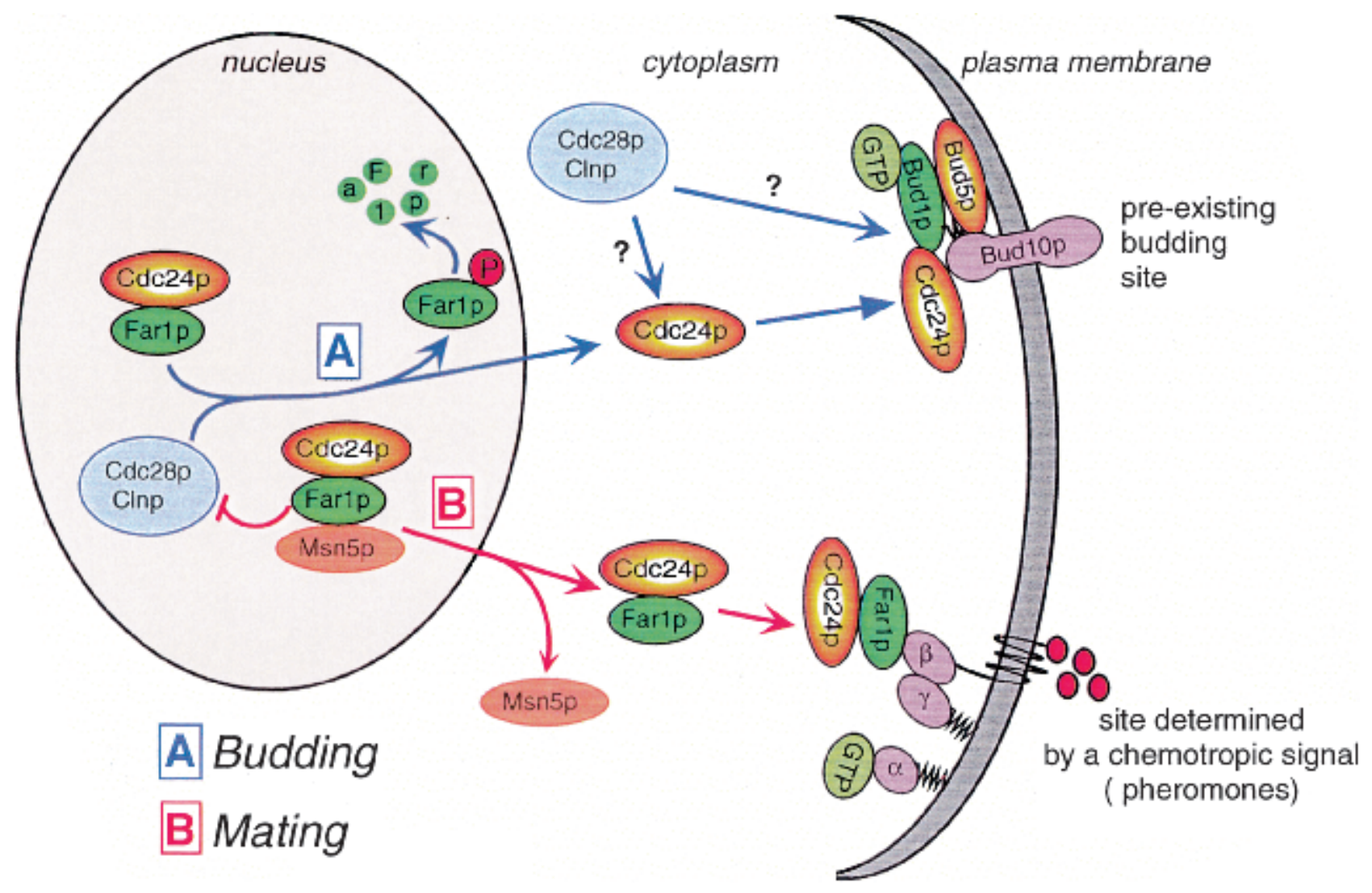

Figure 3. Regulation of Cdc24p membrane targeting during budding and mating. In the $\mathrm{G}_{1}$ phase of the cell cycle, Cdc24p is sequestered in the nucleus by Farlp. Pathway A: At bud emergence, activation of the $\mathrm{G}_{1}$ cyclin-CDK complex Cdc28p-Clnp triggers phosphorylation and subsequent ubiquitin-dependent degradation of Far1p. As a consequence, Cdc24p redistributes to the cytoplasm. In addition, Cdc28p-Clnp promotes the recruitment of Cdc24p to the preexisting budding site by an unknown mechanism. Recruitment and activation of Cdc24p by Rsrlp/Budlp-GTP at the predetermined budding site allows polarization of the actin cytoskeleton toward that site. Pathway B: In the presence of a gradient of secreted pheromones, the kinase complex Cdc28p-Clnp is inhibited and Farlp is stabilized. The Farlp-Cdc24p complex is exported by the exportin Msn5p, and Farlp targets Cdc24p to G $\beta \gamma$ at the site of activated receptor. Recruitment and activation of Cdc $24 \mathrm{p}$ then allows polarization of the actin cytoskeleton toward the mating partner. 
that Bud5p may be recruited to the incipient bud site by binding to Axl2p/Bud10p. Polarized localization of Bud5p and Bud2p are mutually interdependent (H.-O. Park, pers. comm.), and maintenance of Bud2p at the polarization site requires Rsr1p/Bud1p (Park et al. 1999). Thus, both the GAP and GEF of Rsrlp/Bud1p colocalize at the incipient bud site and may locally modulate the rapid cycling of Rsrlp/Budlp between its GDP- and GTP-bound states. Taken together, these results suggest that Rsrlp/Budlp is an important regulator of Cdc $24 p$, which may recruit Cdc24p to the incipient bud site (Figs. 2A, 3). Importantly, preliminary evidence suggests that Rsrlp/Budlp may not only recruit but also activate Cdc24p at the plasma membrane. Rsrlp/Budlp interacts with the conserved $\mathrm{CH}$ motif in the $\mathrm{N}$-terminal regulatory domain of Cdc24p (Fig. 2B; Y. Shimada and M. Peter, unpubl.), which is involved in its activation in vivo. We propose that the $\mathrm{N}$-terminal domain of Cdc24p inhibits its catalytic DH-domain and that binding of Rsrlp/ Budlp to the $\mathrm{CH}$ domain of $\mathrm{Cdc} 24 \mathrm{p}$ relieves this autoinhibition, thereby activating the GEF (Fig. 2B; see below). Thus, local activation of Rsrlp/Budlp may spatially and temporally activate Cdc $24 \mathrm{p}$, implying that a cascade of two GTPases triggers polarization toward the bud site in the $G_{1}$ phase of the cell cycle (Fig. 2A). Because deletion of $B U D 2$ is lethal in cells lacking Cln $1 p$ and $C \ln 2 \mathrm{p}$ (Benton et al. 1993; Cvrckova and Nasmyth 1993), it is tempting to speculate that the Rsrlp/Bud1p module is regulated by the Cdc28p-Clnp kinase. However, in contrast to Cdc24p and Cdc28p-Clnp, the Rsrlp/ Bud1p GTPase module is not essential for viability, implying that other regulators must exist that activate Cdc24p in the absence of Rsrlp/Bud1p (Fig. 2B).

\section{Recruitment and activation of Cdc24p in a morphogenetic gradient during mating}

To ensure efficient conjugation, two mating partners have to grow toward each other for subsequent fusion. The two cells are able to locate each other by interpreting a pheromone gradient and to polarize their actin cytoskeleton in the direction of the highest pheromone concentration. Pheromones bind to cell-type specific seven-transmembrane receptors (Ste2p or Ste3p), which in turn activate the associated heterotrimeric $\mathrm{G}$ protein ( $\alpha, \beta, \gamma$ encoded by GPA1, STE4, and STE18 respectively), by inducing its dissociation into G $\alpha-\mathrm{GTP}$ and G $\beta \gamma$ subunits (Sprague and Thorner 1992; Leberer et al. 1997). It has been estimated that as little as a $1 \%$ difference in receptor occupancy is sufficient to correctly orient the cytoskeleton in the morphogenetic gradient (Segall 1993), suggesting that mechanisms must exist that amplify small differences to stabilize the axis of polarization.

Formation of an oriented mating projection requires the same basic polarization machinery as bud emergence. However, activation of Cdc $42 \mathrm{p}$ does not occur at the presumptive bud site but, instead, Cdc42p is specifically activated at a new site determined by the morphogenetic signal. Thus, cells have to override their internal budding program and target the polarization machinery to the site of maximal receptor activation. The spatial information of the pheromone gradient is transduced intracellularly by the G $\beta \gamma$ heterodimer, which guides the Cdc42p-module to the correct site. The critical effector mediating this response is Farlp, which binds via two separable domains to G $\beta \gamma$ and Cdc24p (Butty et al. 1998). Thus, Farlp functions as an adapter, which recruits Cdc24p to activated G $\beta \gamma$ during mating (Figs. 2A,3). Recent evidence suggests that Farlp may not only recruit Cdc24p to the correct site but that, like Rsrlp/Bud1p, Farlp binds to the $\mathrm{CH}$-domain of Cdc24p (Nern and Arkowitz 1998) and may be involved in its activation at the plasma membrane. Thus, Farlp and Rsrlp/Budlp may play analogous roles under different physiological conditions: Rsr1p/Bud1p may target and activate Cdc24p specifically at an intrinsic polarity cue (bud site) during the cell cycle, whereas Farlp may target and activate Cdc24p at a site determined by an extracellular signal (pheromone gradient) during mating (Fig. 2A). How is the positional information of the bud site overridden in the presence of a mating partner? Recent evidence provides some intriguing answers to this question (Fig. 3): Whereas activation of Cdc28p-Clnp at bud emergence triggers degradation of Farlp, inhibition of Cdc28p-Clnp by pheromones stabilizes Farlp (Blondel et al. 2000). This allows the exportin Msn5p to relocate the FarlpCdc24p complex into the cytoplasm (Blondel et al. 1999), where it can bind to G $\beta \gamma$ at the plasma membrane (Nern and Arkowitz 2000b; Shimada et al. 2000). We propose that when complexed with Farlp, Cdc24p is unable to interact with Rsrlp/Budlp at the incipient bud site, thereby favoring targeting of $\mathrm{Cdc} 24 \mathrm{p}$ to the mating site (Fig. 3). Thus, regulated nuclear retention of Cdc24pFarlp complexes may allow cells to choose between a preexisting landmark and an extracellular signal-mediated landmark to establish polarity $\left(\mathrm{O}^{\prime}\right.$ Shea and Herskowitz 2000).

\section{Stabilization of Cdc24p at the polarization site}

After recruitment and activation of Cdc $24 p$ at a specific site at the plasma membrane, the polarization complex needs to be stabilized to maintain production of Cdc42pGTP and, thus, polar growth. Binding to Cdc24p inhibits the intrinsic as well as GAP-stimulated GTPase activity of Rsrlp/Bud1p (Zheng et al. 1995; Park et al. 1997). Cdc24p thus stabilizes the GTP-bound form of Rsr1p/ Bud1p, and this reinforces the Rsrlp/Bud1p-Cdc24p interaction (Zheng et al. 1995). Through a C-terminal domain, Cdc24p also interacts with the adapter molecule Bemlp (Peterson et al. 1994), which contains two SH3domains (Chenevert et al. 1992). Interestingly, Cdc24p is able to localize to the incipient bud site in bem1s cells, but binding of Cde $24 \mathrm{p}$ to Bem $1 \mathrm{p}$ is required to stabilize active Cdc24p at the plasma membrane (Gulli et al. 2000). As a consequence, bem $1 \Delta$ cells fail to grow in a polar manner, implying that the continued production of Cdc42p-GTP is responsible for polar bud growth /Gulli et al. 2000). Although Bem1p is unable to activate Cdc24p 
in vitro (Zheng et al. 1995), it is possible that binding of Bem $1 p$ to Cdc $24 p$ stabilizes its active conformation. Interestingly, Bem 1p also interacts with activated Cdc42p (Butty et al. 1998; Bose et al. 2001), and recruitment of Bem1p to the polarization site is dependent on Cdc42pGTP (A.-C. Butty and M. Peter, unpubl.), providing a positive feedback loop that locally stabilizes activated Cdc24p at the plasma membrane. In addition, Bem $1 p$ has been shown to interact preferentially with GDP-bound Rsr1p/Bud1p (Park et al. 1997). Thus, after conversion of Rsrlp/Budlp to its GDP-bound form, Bem1p may replace Rsrlp/Budlp and stabilize activated Cdc24p complexes at the incipient bud site, thereby promoting efficient bud emergence. Consistent with such a model, combination of a BUD5 mutation (which is expected to reduce Rsr1p/Bud1p-GTP levels) with a mildly deleterious mutation in BEM1 results in a severe growth defect at high temperatures and accumulation of round unpolarized cells (Chant et al. 1991).

How is activation of $\mathrm{Cdc} 42 \mathrm{p}$ restricted to a single site? It is likely that site-specific activation together with amplification loops that stabilize activated Cdc24p at the plasma membrane prevent polarization toward additional sites. In addition, GAPs or other negative regulators may prevent $\mathrm{Cdc} 42 \mathrm{p}$ from initiating polarization at other sites on the plasma membrane (Richman and Johnson 2000). Intriguingly, Mdglp, which was isolated in a genetic screen for high-gene-dosage suppressors of the mating defects of bem1 mutant cells (Leberer et al. 1996), localizes uniformly to the plasma membrane except to regions of polarized growth. However, the precise role of $\mathrm{Mdg} 1 \mathrm{p}$ in polarized cell growth remains to be elucidated.

It is noteworthy that in contrast to the budding process, an intact actin cytoskeleton is required to maintain polarized localization of Bem1p and Cdc42p (Ayscough and Drubin 1998) at the shmoo tip, suggesting that once an axis of polarization is established, it needs to be constantly reinforced (Nern and Arkowitz 2000a). The mechanisms that are responsible for this stabilization are not known. An intact cytoskeleton is necessary to concentrate the pheromone receptors within the polarized pointed projection (Ayscough and Drubin 1998), where they oligomerize (Overton and Blumer 2000). Thus, clustering of pheromone receptors may increase local signaling and reinforce the axis of polarization. Receptor clustering may result from targeted secretion of newly synthesized receptors to the site of polarization. In addition, unbound receptors may be internalized and degraded while ligand-bound receptors recycle back to the site of receptor activation (Chen and Davis 2000).

\section{Inactivation of $\mathrm{Cdc} 24 \mathrm{p}$ at the site of polarized growth}

During a normal cell cycle, Cdc $24 \mathrm{p}$ is only transiently found at bud tips and dissociates at the end of polar bud growth (Nern and Arkowitz 1999; Shimada et al. 2000). Importantly, removing Cdc24p from bud tips may require the activity of the PAK-like kinase Cla4p (Gulli et al. 2000). Like Cdc24p, Cla4p binds to Bem1p, and for- mation of this complex is required for phosphorylation of Cdc24p in vivo (Bose et al. 2001; Gulli et al. 2000). Interestingly, phosphorylation of Cdc $24 \mathrm{p}$ leads to its dissociation from the complex. Thus, we propose that a negative feedback regulatory mechanism contributes to the inactivation of Cdc24p after bud emergence (Fig. 4): Cdc42p-GTP activates Cla4p, which in a complex with Bem1p, phosphorylates Cdc24p at bud tips. Phosphorylated Cdc24p dissociates from the plasma membrane, thereby ending local Cdc42p-GTP production and, hence, polar bud growth. Consistent with this model, cells expressing a kinase-inactive mutant form of Cla4p accumulate highly elongated cells with Cdc $24 \mathrm{p}, \mathrm{Bem} 1 \mathrm{p}$, and the effector Gic2p at their tips (Gulli et al. 2000). Likewise, certain $c d c 42$ mutants exhibit hyperpolarized bud growth (cdc42V44A and cdc42-129V36T), and at least Cdc42p-V44A fails to interact with Cla4p (Richman et al. 1999; Kozminski et al. 2000). Importantly, this feedback mechanism may help to maintain the proper temporal order of the different steps at bud emergence because inactivation of Cdc $24 \mathrm{p}$ could not occur before

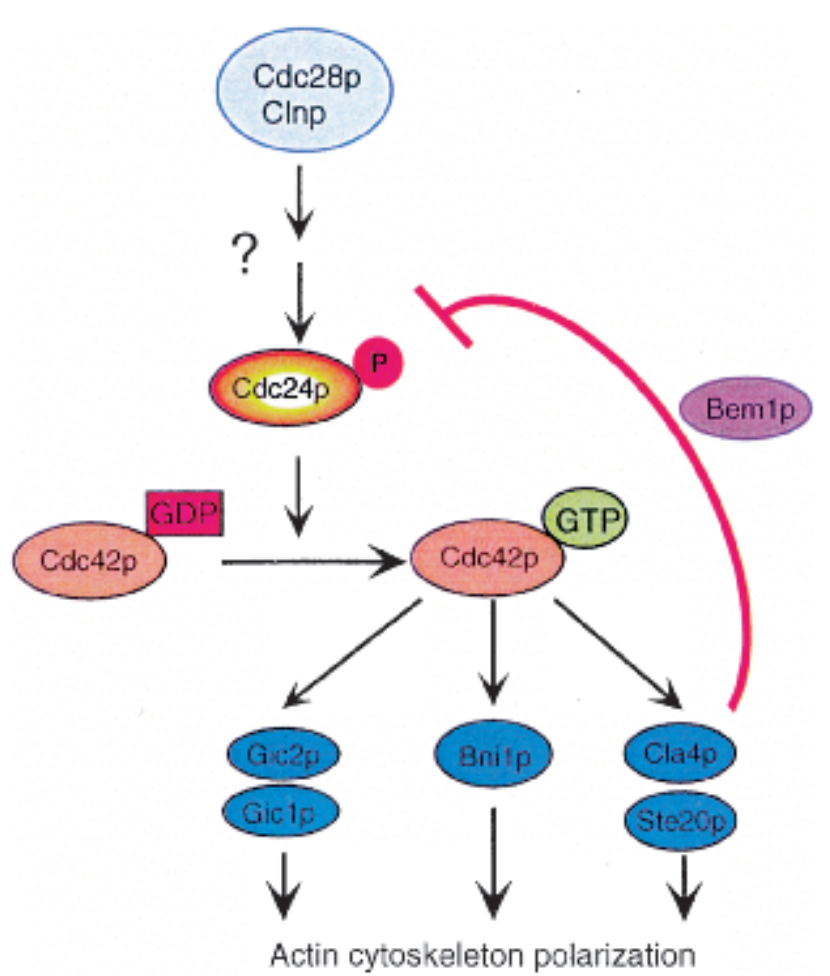

Figure 4. Inactivation of $\mathrm{Cdc} 24 \mathrm{p}$ during budding. Activated Cdc42p (Cdc42p-GTP) interacts with its downstream effectors, including two partially redundant proteins Gic1p and Gic2p, a formin-like protein Bnilp, and two PAK-like kinases Ste20p and Cla4p. In turn, these effectors signal to the actin cytoskeleton polarization machinery. In addition, Cdc42p-GTP activates Cla4p, which in a complex with the adapter protein Bemlp, induces phosphorylation of Cdc24p. Phosphorylated Cdc24p dissociates from Bemlp at bud tips. Thus, phosphorylation of Cdc24p induced by Cla4p may be part of a negative feedback regulatory mechanism, which may serve to stop local activation of $\mathrm{Cdc} 42 \mathrm{p}$ and, hence, polarized growth after bud emergence. 
Cdc42p had been activated and a stable complex with Bemlp had been formed. However, a possible role for the Cdc42p GAPs in switching off polar growth after bud emergence is not excluded, and cells deleted for BEM3 and RGA1 display misshapen cells, some exhibiting an elongated morphology (Stevenson et al. 1995). Therefore, dissociation of Cdc24p and GTP-hydrolysis on Cdc42p by GAPs may together inactivate Cdc42p after bud emergence.

\section{General principles for the regulation of GEFs}

Although in recent years much has been learned on the regulation of cell polarity in budding yeast, it is not clear to what extent similar mechanisms exist in multicellular organisms. Many mammalian Rho-GEFs have been identified, but in most cases their in vivo specificity toward Cdc42, Rac, or Rho GTPases is not clear. Nevertheless, although the mechanistic details may be different, we draw some parallels to the mechanisms of Cdc24p regulation in yeast. We propose that temporal and spatial regulation of mammalian Rho-GEFs can similarly be divided into four basic steps (Fig. 5): First, the appropriate GEF has to be recruited to a specific site at the cell cortex, where, second, it will be activated. In yeast, the molecules that target Cdc24p to the correct site at the plasma membrane may also be responsible for its activation. Third, the activated GEF is stabilized at the plasma membrane by binding to an adapter protein, allowing for a stable platform for the local production of GTP-bound GTPase. Finally, inactivation of the GEF and/or GTP-hydrolysis terminates polarized GTPase signaling. Below, we discuss some selected examples to illustrate that these four steps may also be useful to describe the regulation of Rho-GEFs in multicellular organisms. For a detailed discussion of the regulation of mammalian GEFs, we alert the reader to recently published reviews (Cerione and Zheng 1996; Bustelo 2000; Symons and Settleman 2000).

\section{Membrane recruitment of mammalian GEFs by binding to activated receptors}

During yeast mating, polarization is initiated by specifically targeting Cdc $24 \mathrm{p}$ to the site of receptor activation at the plasma membrane. Similarly, there is now increasing evidence for the translocation of many Rho-GEFs to the plasma membrane on receptor engagement (Fig. 5). Among the best-characterized mammalian GEFs is Vav1, which binds to activated T-cell or B-cell receptors (TCR and BCR, respectively) to induce transcriptional activation and cytoskeletal reorganization (Bustelo 2000). In addition, the broadly expressed Vav2 and Vav3 isoforms are recruited to the plasma membrane by binding via their SH2 (re-homology 2) domains to the EGF and PDGF receptors in HeLa cells. In some cases, binding to the receptors is not direct but may be bridged by adapter molecules (see below). Membrane association of Vav1 and other GEFs is likely to require the cooperative function of receptor binding and the N-terminal $\mathrm{PH}$ domain, which is able to bind phosphatidylinositol derivatives PI(3,4)P2 (PIP2) and PI(3,4,5)P3 (PIP3). These PIPs are produced by PI kinases, which may themselves be activated by tyrosine kinase receptors (Katada et al. 1999|. Thus, maximal activation of Rho-type GEFs may involve the cooperative action of two signals: one recruiting the GEF to the membrane, and the other locally producing PIPs. The PH domain of yeast Cdc $24 \mathrm{p}$ is important for the function of Cde $24 \mathrm{p}$ in vivo (Y. Shimada and M. Peter, unpubl.), but it is not known whether it interacts with PIPs. Finally, although some mammalian GEFs have been detected in the nucleus /Clevenger et al. 1995; Bertagnolo et al. 1998; Ichiba et al. 1999; Adam et al. 2000), no functional significance for their regulation has been described.

Recent evidence suggests that at least some mammalian GTPases may themselves be targeted independently to specific sites at the cell cortex (Gingras et al. 1998) and, thus, restrict GTPase activity to these cortical domains. It is possible that the C-terminal isoprene modification of GTPases contributes to their recruitment to membrane microdomains such as caveolae (Michaely et al. 1999). Localized GTPase activation is of particular relevance for Rac and $\mathrm{Cdc} 42$ that play essential roles in directed cell migration and cell polarity. Coordinated translocation of both GEFs and GTPases to a specific membrane compartment may increase the efficiency of the nucleotide exchange reaction and prevent spontaneous activation of GTPases.

\section{Membrane recruitment of Rho-GEFs in response to integrin activation: a role for Rap1-like GTPases}

In the examples above, Vav is thought to directly bind to activated receptors, whereas in yeast, the recruitment of Cdc24p to the plasma membrane requires Farlp or the small GTPase Rsrlp/Bud1p. However, a role for Rap1GTPases in integrin signaling has recently emerged (Caron et al. 2000; Katagiri et al. 2000; Reedquist et al. 2000). The extracellular matrix (ECM) controls cell morphology and migration and signals directly to cells through transmembrane receptors such as integrins (Fig. 5A). Ligand binding to integrins leads to their clustering and subsequent recruitment of actin filaments to the cytoplasmic domain of integrins (Schoenwaelder and Burridge 1999). It was shown recently that adhesion of fibroblasts to fibronectin promotes transient Rac activation (Price et al. 1998; del Pozo et al. 2000) and more prolonged activation of Rho (Ren et al. 1999), demonstrating that integrin engagement by ligand leads to activation of Rho-type GTPases, presumably through activation of a GEF. Interestingly, mammalian Rap1 (also called Krev-1 or smg21A) has been implicated in controlling cellular adhesion by modulating integrin function (Reedquist et al. 2000), and Rapl is required for integrin-dependent phagocytosis (Caron et al. 2000). Rapl is similar in sequence to yeast Rsrlp/Budlp (Bender and Pringle 1989), and indeed, mammalian 


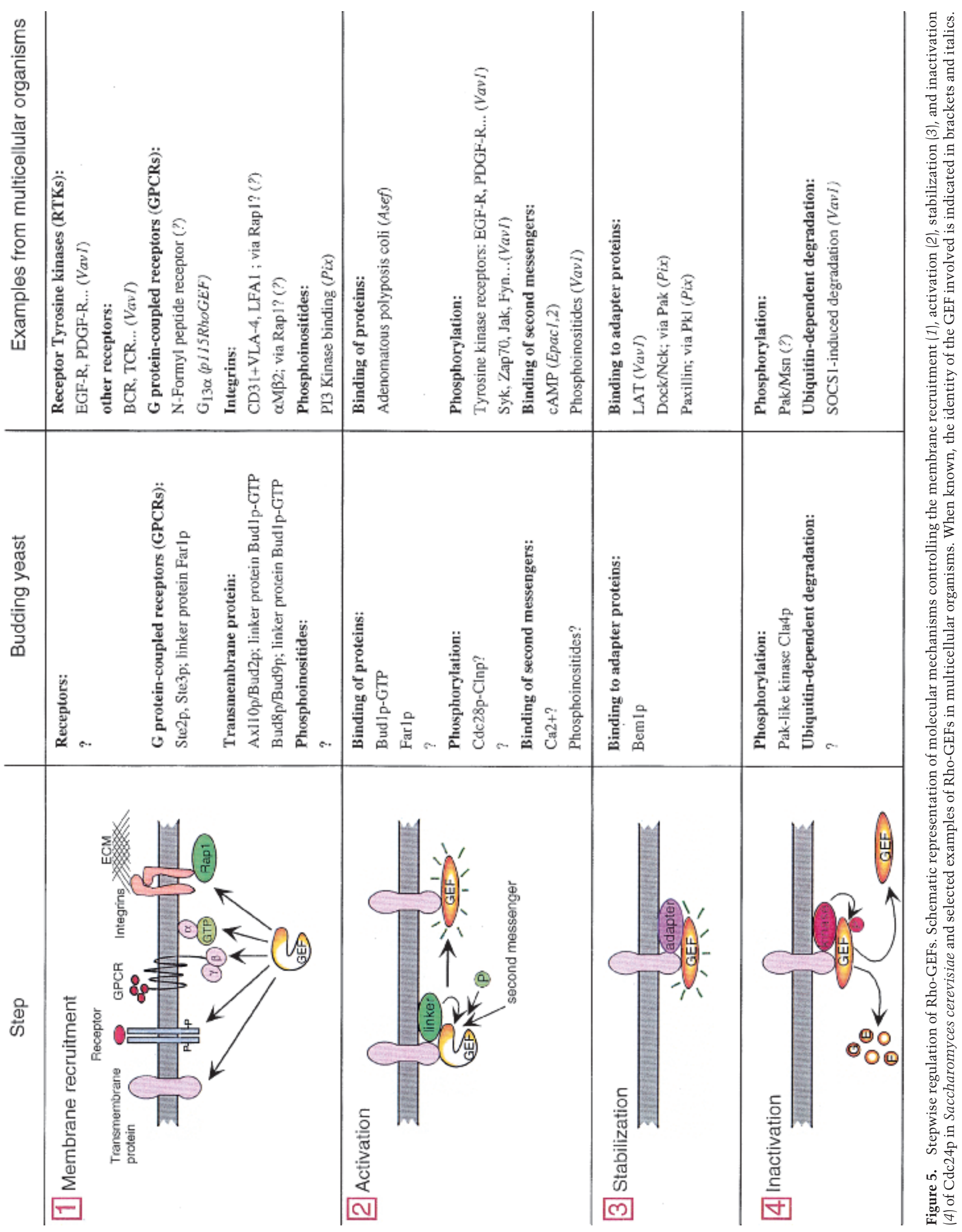


Rap1A can suppress the growth defect of $c d c 24-4$ temperature sensitive (ts) cells (Ruggieri et al. 1992). Putative Rap1-homologs are also present in Caenorhabditis elegans and Drosophila. In flies, Rap1 mutations disrupt cell migration and cause abnormal cell shapes (Asha et al. 1999), suggesting that Rap1 is a critical regulator of morphogenesis in vivo, possibly by regulating integrin function. The role of Rap1 in integrin signaling and control of morphogenesis is not clear, but by analogy to yeast, we speculate that Rap 1 may recruit and activate a Rho-GEF. The endogenous GEFs that control activation of GTPases by integrins are not known. However, Vav1 has been implicated in integrin signaling, and integrinmediated adhesion increases tyrosine phosphorylation of Vav in several cell types (Bustelo 2000). Several Vav isoforms contain a $\mathrm{CH}$ motif in their $\mathrm{N}$-terminal domain, which at least in Cdc24p is required for the interaction with Rsrlp/Budlp. However, it is not known at present whether Vav or other Rho-GEFs are effectors of Rap1 GTPases.

\section{Membrane-recruitment of Rho-GEFs by activated heterotrimeric $\mathrm{G}$-proteins}

As in yeast, heterotrimeric G proteins are implicated in the establishment of cell polarity in several organisms and orient cell migration and asymmetric cell division in response to extracellular chemoattractants or intracellular polarity cues. Neutrophils respond to a large number of chemotactic signals, including formylated peptides produced by bacteria, the C5a component of the complement system, and several chemokines produced by endothelial cells, immunocytes, and other inflammatory cells at sites of tissue injury (Weiner et al. 2000). All these signals activate specific G-protein coupled receptors (GPCR) coupled to the $\mathrm{G}_{\mathrm{i}}$ class of trimeric G-proteins, leading to dissociation of $\mathrm{G} \alpha$ and $\mathrm{G} \beta \gamma$, which are thought to activate $\mathrm{Cdc} 42$ and $\mathrm{Rac} 1$ required for actin rearrangements during chemotaxis /Glogauer et al. 2000). Interestingly, recent evidence suggests that Racdependent actin reorganization following activation of the N-formyl-methionyl-leucyl-phenylalanine tripeptide (FMLP) receptor (FPR) is mediated through G $\beta \gamma$ and class Ia PIP3 kinase (Belisle and Abo 2000), but the GEF mediating this response remains to be identified. Moreover, $\mathrm{G}_{13 \alpha}$ has been shown to bind and activate the p115Rho-GEF (Hart et al. 1998). Thus, similar to the pheromone response in yeast, Rho-GEFs may be recruited to and activated at GPCRs by directly or indirectly interacting with activated heterorimeric G proteins.

Spatial activation of specific heterotrimeric $\mathrm{G}$ proteins may also be responsible for orientation of the plane of cell cleavage during asymmetric divisions in early Drosophila and C. elegans embryos. Genetic evidence suggests that $\mathrm{G} \alpha$ and $\mathrm{G} \beta \gamma$ are both required for spindle orientation in early C. elegans embryos (Gotta and Ahringer 2001). Interestingly, G $\beta \gamma$ is important in regulating centrosome migration around the nucleus and, hence, in orienting the mitotic spindle, whereas $\mathrm{G} \alpha$ is required for asymmetric spindle positioning. Recent results from asymmetric cell divisions in the Drosophila nervous system now suggest that heterotrimeric G proteins may be locally activated in a receptor-independent manner (Schweissguth 2000). Pins (partner of inscuteable) is required for oriented cell division and was found to specifically bind to $\mathrm{G} \alpha$-subunits through its Go-Locodomains (Siderovski et al. 1999). Pins homologs are also found in man and C. elegans, but it is not known whether they are involved in the regulation of cell polarity. In addition, database searches have identified GoLoco domains in several proteins (K. Hoffmann, pers. commun.), some of which may be involved in activating heterotrimeric $\mathrm{G}$ proteins in response to a wide variety of internal signals or asymmetric determinants. Available evidence suggests that Pins may be functionally analogous to GPCRs in that it is able to bind G $\alpha$ subunits (Schaefer et al. 2000) and locally liberating activated G $\beta \gamma$ heterodimers. Indeed, expression of the GoLoco domains of Pins is able to activate the pheromone response pathway in yeast cells lacking the pheromone receptor (Cismowski et al. 1999), suggesting that Pins may activate G $\beta \gamma$ in a receptor-independent fashion. Because the Pins protein is asymmetrically localized by virtue of its ability to bind to the polarity determinant Inscuteable (Schaefer et al. 2000; Yu et al. 2000), it may be able to activate heterotrimeric $\mathrm{G}$ proteins at specific sites. The G $\alpha$ and G $\beta \gamma$ effectors that mediate the cytoskeletal response are not known, but it is likely that they will activate Cdc42 or other Rho GTPases. Drosophila Cdc42 has been identified (Sasamura et al. 1997), but a function in asymmetric cell division has not been demonstrated. In contrast, RNAi experiments in C. elegans embryos suggest that $\mathrm{Cdc} 42$ is required for asymmetric spindle positioning (Jantsch-Plunger et al. 2000; M. Gotta, pers. comm.). Activated $\mathrm{Cdc} 42$ has recently been shown to interact with Par6, Par3, and PKC $\zeta$ (Joberty et al. 2000; Lin et al. 2000; Qiu et al. 2000), which are required for asymmetric cell divisions and spindle positioning. No proteins with obvious homology to Farlp have been found; thus, it remains to be determined how GEFs are targeted to activated G $\alpha$ and G $\beta \gamma$ in these systems.

\section{Activation of Rho-GEFs at the plasma membrane}

Although the activation of yeast Cdc24p at the plasma membrane remains elusive, this step is comparably well understood in several mammalian Rho-GEFs. The available evidence strongly suggests that the catalytic domain of many Rho-GEFs is inhibited intramolecularly by its $\mathrm{N}$-terminal regulatory domain. Mutant forms, which have truncations of their $\mathrm{N}$-terminal domain, are constitutively active and often exhibit oncogenic activity (Cerione and Zheng 1996; Whitehead et al. 1997). Recently, structural determination confirmed that the Dblhomology domain of Vav1 is autoinhibited by an N-terminal extension, which lies in the GTPase-interaction site. Thus, activation of Rho-type GEFs is likely to involve dissociation of an intramolecular inhibitory do- 
main from the catalytic Dbl-domain, which may be achieved by binding to a transmembrane receptor or an activator protein such as Rsrlp/Bud1p or Farlp (Fig. 2B), to a second messenger, or by posttranslational modification including phosphorylation.

A strong case for the activation of Vavl by tyrosine phosphorylation has recently emerged. Vav1 is phosphorylated on Tyr 174 by proximal tyrosine kinases on receptor stimulation and membrane recruitment, and this phosphorylation strongly increases its exchange activity (Crespo et al. 1997; Han et al. 1997). Indeed, NMR spectroscopy data show that the $\mathrm{N}$-terminal inhibitory domain encompassing Tyr 174 is released from the Dblhomology domain on phosphorylation (Aghazadeh et al. 2000), demonstrating that tyrosine phosphorylation relieves autoinhibition by exposing the GTPase interaction surface of the Dbl-homology domain. GEF activity is further promoted by PIP2 and PIP3, which bind to its $\mathrm{PH}$ domain (Han et al. 1998). GEFs of the Vav or Pix family also contain an $\mathrm{N}$-terminal $\mathrm{CH}$ domain that, in Cdc24p, appears to interact with its activators Rsrlp/ Budlp and Farlp (Fig. 2B). It is thus possible that binding of a GTPase or other activators to the $\mathrm{CH}$ domain of Vav cooperates with tyrosine phosphorylation for full activation, or that binding of activators may be a prerequisite for subsequent tyrosine phosphorylation.

Activation of a Rho-GEF can be triggered by binding of an activator, as illustrated by the following example. Recent evidence shows that the Rac-GEF Asef binds to the tumor suppressor adenomatous polyposis coli (APC; Kawasaki et al. 2000), which links cell adhesion and cell proliferation (Goss and Groden 2000). The activity of Asef is negatively regulated by its $\mathrm{N}$-terminal region, which contains the APC-binding site. Thus, binding of APC is predicted to relieve autoinhibition, thereby allowing the catalytic domain of Asef to interact with Rac1.

Finally, the Rap1-GEFs Epac1 and Epac2 are activated by directly binding to the second messenger cAMP /de Rooij et al. 1998, 2000). In the absence of cAMP, an interaction between the GEF domain and the cAMP-binding domain inhibits the catalytic activity of Epac1. Epac1 becomes activated by a release of this inhibition on cAMP binding. Consistent with this model, deletion of the cAMP-dependent regulatory sequences results in constitutive GEF activity (de Rooij et al. 2000).

Taken together, although these activators are different in nature, they may use a common mechanism, in that they directly bind to the $\mathrm{N}$-terminal domain, thereby relieving autoinhibition imposed on the catalytic domain of GEFs (Fig. 2B). Thus, a search for factors that bind to the regulatory domain of GEFs may be fruitful to identify potential Rho-GEF activators.

\section{Stabilization of GEFs at the plasma membrane by adapters}

A second class of proteins that interact with GEFs are the adapters. In yeast, the adapter Bemlp binds to the $\mathrm{C}$ terminus of Cdc $24 \mathrm{p}$, but this interaction is not essential for Cdc24p activation in vivo (Jaquenoud et al. 1998).
Importantly, Bem $1 \mathrm{p}$ is not required for the recruitment of Cdc24p to the plasma membrane, but it is involved in stabilizing activated Cdc24p at sites of polarization. Many mammalian adapter proteins are involved in GTPase signaling (Buday 1999), but their role in GEF activation or localization is poorly understood. For example, the palmitoylated adapter protein LAT (linker for activation of $\underline{T}$ cell) binds to Vav and thereby facilitates the targeting of Vav to glycolipid-enriched microdomains in activated T cells (Salojin et al. 2000). However, time-lapse microscopy is required to distinguish whether LAT is involved in membrane recruitment or stabilization of Vav at the plasma membrane. An intensively studied adapter protein is Nck, which is composed exclusively of one $\mathrm{SH} 2$ and three $\mathrm{SH} 3$ domains and has been shown to interact with many proline-rich proteins including the GEFs Pix and Trio (McCarty 1998). Nck associates via its $\mathrm{SH} 2$ domain with activated EGF and PDGF receptors and can be recruited into signaling complexes in response to activation of the vertebrate guidance receptors EphB1 and EphB2 (Holland et al. 1997; Stein et al. 1998), two Eph receptor tyrosine kinase family members. Consistent with these findings, the Drosophila Nck homolog Dreadlocks (DOCK) is capable of binding ligand-activated Eph1 (Stein et al. 1998) and has recently been implicated in growth cone guidance and assembly of focal adhesion complexes by binding to Pix and Trio. Indeed, Dock/Nck expression is detected in $\mathrm{R}$-cell growth cones in the target region (Garrity et al. 1996) and is also found in focal adhesions. Thus, the GEFs Trio and Pix together with the adapter Dock/Nck may regulate GTPase activity during photoreceptor axon pathfinding in Drosophila and the formation of focal adhesions in mammalian cells. Finally, paxillin has emerged as a focal adhesion adapter involved in the integration of growth factor- and adhesion-mediated signal transduction pathways (Turner 2000). Paxillin is a multidomain protein that binds and recruits PAK, Nck, and Pix to the plasma membrane, thereby directing GTPasemediated reorganization of the actin-based cytoskeleton (Turner et al. 1999). Thus, Dock/Nck and paxillin may function analogously to Bem $1 p$ in yeast and stabilize the GEFs Pix and Trio at sites of polarized growth.

\section{Inactivation of GEFs: a role for PAK-like kinases?}

In yeast, a negative feedback loop mediated by the PAKlike kinase Cla4p may inactivate Cdc24p at the plasma membrane by inducing its dissociation from the adapter Bemlp (Fig. 4; Gulli et al. 2000). However, Cla4p has also been shown to promote actin polymerization (Eby et al. 1998; Lechler et al. 2000). In mammalian cells, constitutive active Pak1 or overexpression of Cdc42-GTP or Rac1-GTP induces rapid loss of stress fibers and a dramatic loss of focal adhesions, resulting in retraction of the cell periphery in migrating fibroblasts (Manser et al. 1997). These results suggest that activated Pak1 may promote turnover of these structures.

Recent studies on axonal guidance in the Drosophila nervous system provide a beautiful example for the dual 
role of Pak-like kinases in regulating dynamic remodeling of actin structures (Hing et al. 1999). Whereas the directed extension of growth cones leads axons toward their destination, rearrangements of cytoskeletal structures on reaching the target area are required to inhibit growth cone motility and to allow the formation of synaptic connections. Pak1/Msn has been shown to play a role in the shutdown of growth cone motility when axons reach their target region (Ruan et al. 1999): Overexpression of Pak/Msn induces pretarget growth cone termination, and conversely, many growth cones fail to stop at their target lamina in Pak/Msn mutants. Thus, target-derived stop signals may activate Pak/Msn, which in turn coordinates cytoskeletal reorganization in decelerating growth cone motility. Like Bem $1 p$ in yeast, the adapter Dock/Nck forms a complex with Pak1/Msn in growth cones and at the leading edge of embryonic epithelial cells undergoing dorsal closure, where they are found in structures resembling focal adhesions. The axonal stop signal may thus activate the function of Pak/ Msn through Dock/Nck by either positioning the kinase close to its substrate or directly stimulating its activity, leading to termination of the growth cone in the target area. A possible candidate for a regulator of Pak1/Msn is the neuron-specific Rac-effector p35/cdk5, which concentrates at the leading edge of axonal growth cones and regulates neurite outgrowth in cortical neurons in culture. Active p35/Cdk5 causes hyperphosphorylation of Pak1, which results in down-regulation of Pak1 kinase activity (Nikolic et al. 1998). Thus, it is possible that inhibition of p35/cdk5 activates Pak1 at the target lamina, leading to inactivation of growth cone motility. The substrates of Pak/Msn responsible for the stop signal of growth cones or the turnover of focal adhesion complexes are not known, but by analogy with the results in yeast, they may include phosphorylation of GEFs. In this regard, it may be interesting to determine whether Trio or Pix dissociate from tips of growth cones once the neurites reach their target area.

Other than a possible role for Pak-like kinases in the negative regulation of GEFs, it has been reported recently that Vav1 is degraded via the ubiquitin-proteasome system (De Sepulveda et al. 2000). SOCS1 is an inducible $\mathrm{SH} 2$-containing protein that negatively regulates cytokine and growth factor signaling required for thymic development. SOCS1 interacts with elongins $\mathrm{B}$ and $\mathrm{C}$, which are both components of a SCF/VCBubiquitin ligase complex (Tyers and Jorgensen 2000), suggesting that SOCS1 may function as a substrate-specific recognition component for Vav1. Because phosphorylation of several substrates is required for their binding to the SCF complex (Deshaies 1997), phosphorylation of Vav1 may also play a negative role by initiating its subsequent degradation. Taken together, ubiquitindependent degradation of Vav1 may provide a novel mechanism to down-regulate its activity in response to cytokine signaling. It is not known whether a similar mechanism may also apply to Cdc 24 p, although its levels do not fluctuate during the cell cycle (Gulli et al. 2000).

\section{Conclusions}

Studies on Rho-GEFs in yeast and mammalian systems identified many regulators, which we postulate can be grouped in four distinct steps (Fig. 5). Impressive progress has been obtained on the activation step itself: Available results strongly indicate that Rho-GEFs are activated by releasing intracellular inhibition exerted by their $\mathrm{N}$-terminal regulatory domain. Thus, a major future challenge will be to identify the various Rho-GEF activators, which are predicted to bind to their N-terminal domains. In addition, full activation of GEFs may require the cooperation of multiple activators, which may respond to different signal transduction pathways.

An important but poorly understood aspect of RhoGTPase signaling is their local activation. Time-lapse microscopy of Cdc24p-GFP in living cells during yeast budding and mating combined with mutational analysis provided a first glimpse at the dynamic subcellular localization and the regulated assembly and disassembly of GEF complexes at the plasma membrane. However, many of the conclusions about GTPase signaling in mammalian cells are based on overexpression of either constitutively active or dominant-negative mutant forms of GEFs, Rho-type GTPases, or their targets. Because these mutant forms are in most cases uniformly expressed at the cell surface, it is difficult to access local effects. In addition, the existence of feedback loops may further complicate the interpretation of the observed phenotypes. Thus, new tools and experimental approaches are needed to address the dynamic and spatial aspects of GTPase signaling. Recently, a system allowing local recruitment of activated Cdc42p to a cell surface receptor provided interesting insights into local actin polymerization and filapodia formation (Castellano et al. 1999). In addition, an approach (FLAIR) to visualize activated Rho-GTPases based on specific binding domains and fluorescence-resonance energy transfer (FRET) microscopy has been developed, which may allow us to follow GTPase signaling in real-time in vivo (Kraynov et al. 2000).

Although we have focused this review on the regulation of Rho-GEFs, it is likely that intra- and extracellular signals also regulate the localization and/or activity of GAPs and GDIs. Thus, the coordinated control of all these regulators may be required to spatially and temporally activate and inactivate Rho-GTPases in vivo.

\section{Acknowledgments}

We thank H.-O. Park, A. Hall, H. Bos, M. Gotta, J. Knoblich, P. Gönczy, I. Hariharan, Y. Shimada, A.-C. Butty, P. Wiget, and K. Hoffmann for helpful discussion and communicating results before publication. We are grateful to P. Gönczy and R. Iggo for critical reading of the manuscript. M.-P.G. is supported by the Swiss Cancer League, and work in the lab of M.P. is supported by grants from the Swiss National Science Foundation, a Helmut Horten award, and a grant of the HFSPO. 


\section{References}

Adam, L., Bandyopadhyay, D., and Kumar, R. 2000. Interferon- $\alpha$ signaling promotes nucleus-to-cytoplasmic redistribution of p95Vav, and formation of a multisubunit complex involving Vav, Ku80, and Tyk2. Biochem. Biophys. Res. Commun. 267: 692-696.

Aghazadeh, B., Lowry, W.E., Huang, X.Y., and Rosen, M.K. 2000. Structural basis for relief of autoinhibition of the Dbl homology domain of proto-oncogene Vav by tyrosine phosphorylation. Cell 102: 625-633.

Arkowitz, R.A. 1999. Responding to attraction: Chemotaxis and chemotropism in Dictyostelium and yeast. Trends Cell Biol. 9: $20-27$.

Asha, H., de Ruiter, N.D., Wang, M.G., and Hariharan, I.K. 1999. The Rap1 GTPase functions as a regulator of morphogenesis in vivo. EMBO J. 18: 605-615.

Aspenstrom, P. 1999. Effectors for the Rho GTPases. Curr. Opin. Cell Biol. 1: 95-102.

Ayscough, K.R. and Drubin, D.G. 1998. A role for the yeast actin cytoskeleton in pheromone receptor clustering and signalling. Curr. Biol. 8: 927-930.

Bähler, J. and Peter, M. 2000. Cell polarity in yeast. In Frontiers in molecular biology: Cell polarity (ed. D.G. Drubin), pp. 21-77. Oxford University Press, Oxford.

Belisle, B. and Abo, A. 2000. N-formyl peptide receptor ligation induces Rac-dependent actin reorganization through G $\beta \gamma$ subunits and class Ia phosphoinositide 3-kinases. J. Biol. Chem. 275: 26225-26232.

Bender, A. and Pringle, J.R. 1989. Multicopy suppression of the cdc24 budding defect in yeast by CDC42 and three newly identified genes including the ras-related gene RSR1. Proc. Natl. Acad. Sci. 86: 9976-9980.

Benton, B.K., Tinkelenberg, A.H., Jean, D., Plump, S.D., and Cross, F.R. 1993. Genetic analysis of $\mathrm{Cln} / \mathrm{Cdc} 28$ regulation of cell morphogenesis in budding yeast. EMBO J. 12: 52675275 .

Bertagnolo, V., Marchisio, M., Volinia, S., Caramelli, E., and Capitani, S. 1998. Nuclear association of tyrosine-phosphorylated Vav to phospholipase C- $\gamma 1$ and phosphoinositide 3-kinase during granulocytic differentiation of HL-60 cells. FEBS Lett. 441: 480-484.

Bi, E., Chiavetta, J.B., Chen, H., Chen, G.C., Chan, C.S., and Pringle, J.R. 2000. Identification of novel, evolutionarily conserved Cdc42p-interacting proteins and of redundant pathways linking cdc $24 \mathrm{p}$ and cdc $42 \mathrm{p}$ to actin polarization in yeast. Mol. Biol. Cell 11: 773-793.

Blondel, M., Alepuz, P.M., Huang, L.S., Shaham, S., Ammerer, G., and Peter, M. 1999. Nuclear export of Farlp in response to pheromones requires the export receptor Msn5p/Ste21p. Genes \& Dev. 13: 2284-2300.

Blondel, M., Galan, J.M., Chi, Y., Longaretti, C., Lafourcade, C., Deshaies, R.J., and Peter, M. 2000. Nuclear-specific degradation of Farlp is controlled by the localization of the F-box protein Cdc4p. EMBO J. 19: 6085-6097.

Bose, I., Irazoqui, J.E., Moskow, J.J., Bardes, E.S., Zyla, T.R., and Lew, D.J. 2001. Assembly of scaffold-mediated complexes containing Cdc42p, the exchange factor Cdc24p, and the effector Cla4p required for cell cycle regulated phosphorylation of Cdc24p. J. Biol. Chem. (in press).

Bottomley, M.J., Salim, K., and Panayotou, G. 1998. Phospholipid-binding protein domains. Biochim. Biophys. Acta 1436: $165-183$.

Buday, L. 1999. Membrane-targeting of signalling molecules by SH2/SH3 domain-containing adaptor proteins. Biochim. Biophys. Acta 1422: 187-204.
Bustelo, X.R. 2000. Regulatory and signaling properties of the Vav family. Mol. Cell. Biol. 20: 1461-1477.

Butty, A.C., Pryciak, P.M., Huang, L.S., Herskowitz, I., and Peter, M. 1998. The role of Farlp in linking the heterotrimeric $\mathrm{G}$ protein to polarity establishment proteins during yeast mating. Science 282: 1511-1516.

Caron, E., Self, A.J., and Hall, A. 2000. The GTPase Rap1 controls functional activation of macrophage integrin $\alpha \mathrm{M} \beta 2$ by LPS and other inflammatory mediators. Curr. Biol. 10: $974-$ 978.

Castellano, F., Montcourrier, P., Guillemot, J.C., Gouin, E., Mechesky, L., Cossart, P., and Chavrier, P. 1999. Inducible recruitment of Cdc42 or WASP to a cell-surface receptor triggers actin polymerization and filopodium formation. Curr. Biol. 8: 351-360.

Cerione, R.A. and Zheng, Y. 1996. The Dbl family of oncogenes. Curr. Opin. Cell Biol. 8: 216-222.

Chant, J. 1999. Cell polarity in yeast. Annu. Rev. Cell Dev. Biol. 15: 365-391.

Chant, J., Corrado, K., Pringle, J.R., and Herskowitz, I. 1991. Yeast BUD5, encoding a putative GDP-GTP exchange factor, is necessary for bud site selection and interacts with bud formation gene BEM1. Cell 65: 1213-1224.

Chen, L. and Davis, N.G. 2000. Recycling of the yeast a-factor receptor. J. Cell Biol. 151: 731-738.

Chenevert, J., Corrado, K., Bender, A., Pringle, J., and Herskowitz, I. 1992. A yeast gene (BEM1) necessary for cell polarization whose product contains two $\mathrm{SH} 3$ domains. Nature 356: 77-79.

Cismowski, M.J., Takesono, A., Ma, C., Lizano, J.S., Xie, X., Fuernkranz, H., Lanier, S.M., and Duzic, E. 1999. Genetic screens in yeast to identify mammalian nonreceptor modulators of G-protein signaling. Nat. Biotechnol. 17: 878-883.

Clevenger, C.V., Ngo, W., Sokol, D.L., Luger, S.M., and Gewirtz, A.M. 1995. Vav is necessary for prolactin-stimulated proliferation and is translocated into the nucleus of a T-cell line. J. Biol. Chem. 270: 13246-13253.

Crespo, P., Schuebel, K.E., Ostrom, A.A., Gutkind, J.S., and Bustelo, X.R. 1997. Phosphotyrosine-dependent activation of Rac-1 GDP/GTP exchange by the vav proto-oncogene product. Nature 385: 169-172.

Cvrckova, F. and Nasmyth, K. 1993. Yeast G1 cyclins CLN1 and CLN2 and a GAP-like protein have a role in bud formation. EMBO T. 12: 5277-5286.

del Pozo, M.A., Price, L.S., Alderson, N.B., Ren, X.D., and Schwartz, M.A. 2000. Adhesion to the extracellular matrix regulates the coupling of the small GTPase Rac to its effector PAK. EMBO T. 19: 2008-2014.

de Rooij, J., Zwartkruis, F.J., Verheijen, M.H., Cool, R.H., Nijman, S.M., Wittinghofer, A., and Bos, J.L. 1998. Epac is a Rapl guanine-nucleotide-exchange factor directly activated by cyclic AMP. Nature 396: 474-477.

de Rooij, J., Rehmann, H., van Triest, M., Cool, R.H., Wittinghofer, A., and Bos, J.L. 2000. Mechanism of regulation of the Epac family of cAMP-dependent RapGEFs. J. Biol. Chem. 275: 20829-20836.

De Sepulveda, P., Ilangumaran, S., and Rottapel, R. 2000. Suppressor of cytokine signaling-1 inhibits VAV function through protein degradation. I. Biol. Chem. 275: 1400514008.

Deshaies, R.J. 1997. Phosphorylation and proteolysis: Partners in the regulation of cell division in budding yeast. Curr. Opin. Genet. Dev. 7: 7-16.

Drubin, D.G. 2000. Cell Polarity. In Frontiers in molecular biology: Cell polarity (ed. D.G. Drubin), pp. 1-320. Oxford University press, Oxford. 
Eby, J.J., Holly, S.P., van Drogen, F., Grishin, A.V., Peter, M., Drubin, D.G., and Blumer, K.J. 1998. Actin cytoskeleton organization regulated by the PAK family of protein kinases. Curr. Biol. 8: 967-970.

Garrity, P.A., Rao, Y., Salecker, I., McGlade, J., Pawson, T., and Zipursky, S.L. 1996. Drosophila photoreceptor axon guidance and targeting requires the dreadlocks $\mathrm{SH} 2 / \mathrm{SH} 3$ adapter protein. Cell 85: 639-650.

Gingras, D., Gauthier, F., Lamy, S., Desrosiers, R.R., and Beliveau, R. 1998. Localization of RhoA GTPase to endothelial caveolae-enriched membrane domains. Biochem. Biophys. Res. Commun. 247: 888-893.

Glogauer, M., Hartwig, J., and Stossel, T. 2000. Two pathways through Cdc42 couple the $\mathrm{N}$-formyl receptor to actin nucleation in permeabilized human neutrophils. I. Cell Biol. 150: 785-796.

Goss, K.H. and Groden, J. 2000. Biology of the adenomatous polyposis coli tumor suppressor. J. Clin. Oncol. 18: 19671979.

Gotta, M. and Ahringer, J. 2001. Distinct roles for Ga and Gbg in regulating spindle position and orientation in early $C$. elegans embryos. Nat. Cell Biol. (in press).

Gulli, M.-P., Jaquenoud, M., Shimada, Y., Niederhauser, G., Wiget P., and Peter, M. 2000. Phosphorylation of the Cdc42p exchange factor Cdc24p by the PAK-like kinase Cla4p may regulate polarized growth in yeast. Mol. Cell 6: 1155-1167.

Hall, A. 1998. Rho GTPases and the actin cytoskeleton. Science 279: 509-514.

Halme, A., Michelitch, M., Mitchell, E.L., and Chant, J. 1996. Bud10p directs axial cell polarization in budding yeast and resembles a transmembrane receptor. Curr. Biol. 6: 570 579.

Han, J., Das, B., Wei, W., Van Aelst, L., Mosteller, R.-D., Khosravi-Far, R., Westwick, J.-K., Der, C.-J., and Broek, D. 1997. Lck regulates Vav activation of members of the Rho family of GTPases. Mol. Cell. Biol. 17: 1346-1353.

Han, J., Luby-Phelps, K., Das, B., Shu, X., Xia, Y., Mosteller, R.D., Krishna, U.M., Falck, J.R., White, M.A., and Broek, D. 1998. Role of substrates and products of PI 3-kinase in regulating activation of Rac-related guanosine triphosphatases by Vav. Science 279: 558-560.

Hart, M.J., Jiang, X., Kozasa, T., Roscoe, W., Singer, W.D., Gilman, A.G., Sternweis, P.C., and Bollag, G. 1998. Direct stimulation of the guanine nucleotide exchange activity of p115 RhoGEF by Galpha13. Science 280: 2112-2114.

Henchoz, S., Chi, Y., Catarin, B., Herskowitz, I., Deshaies, R.J., and Peter, M. 1997. Phosphorylation- and ubiquitin-dependent degradation of the cyclin-dependent kinase inhibitor Farlp in budding yeast. Genes \& Dev. 11: 3046-3060.

Hing, H., Xiao, J., Harden, N., Lim, L., and Zipursky, S.L. 1999. Pak functions downstream of Dock to regulate photoreceptor axon guidance in Drosophila. Cell 97: 853-863.

Holland, S.J., Gale, N.W., Gish, G.D., Roth, R.A., Songyang, Z., Cantley, L.C., Henkemeyer, M., Yancopoulos, G.D., and Pawson, T. 1997. Juxtamembrane tyrosine residues couple the Eph family receptor EphB2/Nuk to specific SH2 domain proteins in neuronal cells. EMBO J. 16: 3877-3888.

Ichiba, T., Hoshi, Y., Eto, Y., Tajima, N., and Kuraishi, Y. 1999. Characterization of GFR, a novel guanine nucleotide exchange factor for Rap1. FEBS Lett. 457: 85-89.

Jantsch-Plunger, V., Gonczy, P., Romano, A., Schnabel, H., Hamill, D., Schnabel, R., Hyman, A.A., and Glotzer, M. 2000. CYK-4: A Rho family GTPase activating protein (GAP) required for central spindle formation and cytokinesis. $J$. Cell Biol. 149: 1391-1404.
Jaquenoud, M., Gulli, M.P., Peter, K., and Peter, M. 1998. The Cdc42p effector Gic2p is targeted for ubiquitin-dependent degradation by the SCFGrrl complex. EMBO J. 17:53605373.

Joberty, G., Petersen, C., Gao L., and Macara, I.G. 2000. The cell-polarity protein Par6 links Par3 and atypical protein kinase C to Cdc42. Nat. Cell. Biol. 2: 531-539.

Johnson, D.I. 1999. Cdc42: An essential Rho-type GTPase controlling eukaryotic cell polarity. Microbiol. Mol. Biol. Rev. 63: 54-105.

Kaibuchi, K., Kuroda, S., and Amano, M. 1999. Regulation of the cytoskeleton and cell adhesion by the Rho family GTPases in mammalian cells. Annu. Rev. Biochem. 68: 459-486.

Katada, T., Kurosu, H., Okada, T., Suzuki, T., Tsujimoto, N., Takasuga, S., Kontani, K., Hazeki, O., and Ui, M. 1999. Synergistic activation of a family of phosphoinositide 3-kinase via G-protein coupled and tyrosine kinase-related receptors. Chem. Phys. Lipids 98: 79-86.

Katagiri, K., Hattori, M., Minato, N., Irie, S., Takatsu, K., and Kinashi, T. 2000. Rapl is a potent activation signal for leukocyte function-associated antigen 1 distinct from protein kinase $\mathrm{C}$ and phosphatidylinositol-3-OH kinase. Mol. Cell. Biol. 20: 1956-1969.

Kawasaki, Y., Senda, T., Ishidate, T., Koyama, R., Morishita, T., Iwayama, Y., Higuchi, O., and Akiyama, T. 2000. Asef, a link between the tumor suppressor APC and G-protein signaling. Science 289: 1194-1197.

Kozminski, K.G., Chen, A.J., Rodal, A.A., and Drubin, D.G. 2000. Functions and functional domains of the GTPase Cdc42p. Mol. Biol. Cell 11: 339-354.

Kraynov, V.S., Chamberlain, C., Bokoch, G.M., Schwartz, M.A., Slabaugh, S., and Hahn, K.M. 2000. Localized rac activation dynamics visualized in living cells. Science 290: 333-337.

Kron, S.J. and Gow, N.A. 1995. Budding yeast morphogenesis: Signalling, cytoskeleton and cell cycle. Curr. Opin. Cell Biol. 7: 845-855.

Leberer, E., Chenevert, J., Leeuw, T., Harcus, D., Herskowitz, I., and Thomas, D.Y. 1996. Genetic interactions indicate a role for Mdglp and the SH3 domain protein Bem 1p in linking the G-protein mediated yeast pheromone signalling pathway to regulators of cell polarity. Mol. Gen. Genet. 252: 608-621.

Leberer, E., Thomas, D.Y., and Whiteway, M. 1997. Pheromone signalling and polarized morphogenesis in yeast. Curr. Opin. Genet. Dev. 7: 59-66.

Lechler, T., Shevchenko, A., and Li, R. 2000. Direct involvement of yeast type I myosins in Cdc42-dependent actin polymerization. J. Cell Biol. 148: 363-373.

Lew, D.J. and Reed, S.I. 1995. Cell cycle control of morphogenesis in budding yeast. Curr. Opin. Genet. Dev. 5: 17-23.

Lin, D., Edwards, A.S., Fawcett, J.P., Mbamalu, G., Scott, J.D., and Pawson, T. 2000. A mammalian PAR-3-PAR-6 complex implicated in Cdc42/Rac1 and aPKC signalling and cell polarity. Nat. Cell Biol. 2: 540-547.

Manser, E., Huang, H.Y., Loo, T.H., Chen, X.Q., Dong, J.M., Leung, T., and Lim, L. 1997. Expression of constitutively active $\alpha$-PAK reveals effects of the kinase on actin and focal complexes. Mol. Cell. Biol. 17: 1129-1143.

McCarty, J.H. 1998. The Nck SH2/SH3 adaptor protein: A regulator of multiple intracellular signal transduction events. Bioessays 20: 913-921.

Michaely, P.A., Mineo, C., Ying, Y.S., and Anderson, R.G. 1999. Polarized distribution of endogenous Racl and RhoA at the cell surface. J. Biol. Chem. 274: 21430-21436.

Michelitch, M. and Chant, J. 1996. A mechanism of Bud1p GTPase action suggested by mutational analysis and immunolocalization. Curr. Biol. 6: 446-454. 
Nern, A. and Arkowitz, R.A. 1998. A GTP-exchange factor required for cell orientation. Nature 391: 195-198.

- 1999. A Cdc24p-Farlp-G $\beta \gamma$ protein complex required for yeast orientation during mating. J. Cell Biol. 144: 11871202.

- 2000a. G proteins mediate changes in cell shape by stabilizing the axis of polarity. Mol. Cell 5: 853-864.

- 2000b. Nucleocytoplasmic shuttling of the Cdc42p exchange factor Cdc24p. J. Cell Biol. 148: 1115-1122.

Nikolic, M., Chou, M.M., Lu, W., Mayer, B.J., and Tsai, L.H. 1998. The p35/Cdk5 kinase is a neuron-specific Rac effector that inhibits Pak1 activity. Nature 395: 194-198.

O'Shea, E.K. and Herskowitz, I. 2000. The ins and outs of cellpolarity decisions. Nat. Cell Biol. 2: E39-E41.

Overton, M.C. and Blumer, K.J. 2000. G-protein-coupled receptors function as oligomers in vivo. Curr. Biol. 10: 341-344.

Park, H.O., Bi, E., Pringle, J.R., and Herskowitz, I. 1997. Two active states of the Ras-related Bud1/Rsrl protein bind to different effectors to determine yeast cell polarity. Proc. Nat1. Acad. Sci. 94: 4463-4468.

Park, H.O., Sanson, A., and Herskowitz, I. 1999. Localization of Bud2p, a GTPase-activating protein necessary for programming cell polarity in yeast to the presumptive bud site. Genes \& Dev. 13: 1912-1917.

Peterson, J., Zheng, Y., Bender, L., Myers, A., Cerione, R., and Bender, A. 1994. Interactions between the bud emergence proteins Bem 1p and Bem2p and Rho-type GTPases in yeast. J. Cell Biol. 127: 1395-1406.

Price, L.S., Leng, J., Schwartz, M.A., and Bokoch, G.M. 1998. Activation of Rac and Cdc42 by integrins mediates cell spreading. Mol. Biol. Cell 9: 1863-1871.

Pruyne, D. and Bretscher, A. 2000. Polarization of cell growth in yeast. I. Establishment and maintenance of polarity states. J. Cell Sci. 113: 365-375.

Qiu, R.G., Abo, A., and Steven Martin, G. 2000. A human homolog of the C. elegans polarity determinant Par-6 links Rac and Cdc42 to PKCzeta signaling and cell transformation. Curr. Biol. 10: 697-707.

Reedquist, K.A., Ross, E., Koop, E.A., Wolthuis, R.M., Zwartkruis, F.J., van Kooyk, Y., Salmon, M., Buckley, C.D., and Bos, J.L. 2000. The small GTPase, Rap1, mediates CD31induced integrin adhesion. J. Cell Biol. 148: 1151-1158.

Ren, X.D., Kiosses, W.B., and Schwartz, M.A. 1999. Regulation of the small GTP-binding protein Rho by cell adhesion and the cytoskeleton. EMBO J. 18: 578-585.

Richman, T.J. and Johnson, D.I. 2000. Saccharomyces cerevisiae $\mathrm{Cdc} 42 \mathrm{p}$ GTPase is involved in preventing the recurrence of bud emergence during the cell cycle. Mol. Cell. Biol. 20: $8548-8559$.

Richman, T.J., Sawyer, M.M., and Johnson, D.I. 1999. The Cdc42p GTPase is involved in a G2/M morphogenetic checkpoint regulating the apical-isotropic switch and nuclear division in yeast. J. Biol. Chem. 274: 16861-16870.

Roemer, T., Madden, K., Chang, J., and Snyder, M. 1996. Selection of axial growth sites in yeast requires Axl2p, a novel plasma membrane glycoprotein. Genes \& Dev. 10: $777-$ 793.

Ruan, W., Pang, P., and Rao, Y. 1999. The SH2/SH3 adaptor protein dock interacts with the Ste20-like kinase misshapen in controlling growth cone motility. Neuron 24: 595-605.

Ruggieri, R., Bender, A., Matsui, Y., Powers, S., Takai, Y., Pringle, J.R., and Matsumoto, K. 1992. RSR1, a ras-like gene homologous to Krev-1 (smg21A/rap1A): Role in the development of cell polarity and interactions with the Ras pathway in Saccharomyces cerevisiae. Mol. Cell. Biol. 12: 758 766.
Salojin, K.V., Zhang, J., Meagher, C., and Delovitch, T.L. 2000 ZAP-70 is essential for the $\mathrm{T}$ cell antigen receptor-induced plasma membrane targeting of SOS and Vav in T cells. $J$. Biol. Chem. 275: 5966-5975.

Sasamura, T., Kobayashi, T., Kojima, S., Qadota, H., Ohya, Y., Masai, I., and Hotta, Y. 1997. Molecular cloning and characterization of Drosophila genes encoding small GTPases of the rab and rho families. Mol. Gen. Genet. 254: 486-494.

Schaefer, M., Shevchenko, A., and Knoblich, J.A. 2000. A protein complex containing inscuteable and the $\mathrm{G} \alpha$-binding protein Pins orients asymmetric cell divisions in Drosophila. Curr. Biol. 10: 353-362.

Schoenwaelder, S.M. and Burridge, K. 1999. Bidirectional signaling between the cytoskeleton and integrins. Curr. Opin. Cell. Biol. 11: 274-286.

Schweissguth, F. 2000. Cell polarity: Fixing cell polarity with Pins. Curr. Biol. 10: R265-R267.

Segall, J.E. 1993. Polarization of yeast cells in spatial gradients of $\alpha$ mating factor. Proc. Natl. Acad. Sci. 90: 8332-8336.

Shimada, Y., Gulli, M.-P., and Peter, M. 2000. Nuclear sequestration of the exchange factor Cdc $24 \mathrm{p}$ by Far1p regulates cell polarity during mating. Nat. Cell Biol. 2: 117-124.

Siderovski, D.P., Diversé-Pierluissi, M.A., and De Vries, L. 1999. The GoLoco motif: A Gai/0 binding motif and potential guanine-nucleotide exchange factor. Trends Biochem. Sci. 24: 340-341.

Sprague, G.F. and Thorner, J.W. 1992. Pheromone response and signal transduction during the mating process of Saccharomyces cerevisiae. In The molecular and cellular biology of the yeast Saccharomyces (ed. E.W. Jones, et al.), pp. 657-744. Cold Spring Harbor Laboratory Press, Cold Spring Harbor, NY.

Stein, E., Huynh-Do, U., Lane, A.A., Cerretti, D.P., and Daniel, T.O. 1998. Nck recruitment to Eph receptor, EphB1/ELK, couples ligand activation to c-Jun kinase. J. Biol. Chem. 273: $1303-1308$.

Stevenson, B.J., Ferguson, B., De, V.C., Bi, E., Pringle, J.R., Ammerer, G., and Sprague, G.J. 1995. Mutation of RGA1, which encodes a putative GTPase-activating protein for the polarity-establishment protein Cdc42p, activates the pheromoneresponse pathway in the yeast Saccharomyces cerevisiae. Genes \& Dev. 9: 2949-2963.

Stradal, T., Kranewitter, W., Winder, S.J., and Gimona, M. 1998. $\mathrm{CH}$ domains revisited. FEBS Lett. 431: 134-137.

Symons, M. and Settleman, J. 2000. Rho family GTPases: More than simple switches. Trends Cell Biol. 10: 415-419.

Takahashi, K., Sasaki, T., Mammoto, A., Takaishi, K., Kameyama, T., Tsukita, S., and Takai, Y. 1997. Direct interaction of the Rho GDP dissociation inhibitor with ezrin/radixin/ moesin initiates the activation of the Rho small G protein. I. Biol. Chem. 272: 23371-23375.

Toenjes, K.A., Sawyer, M.M., and Johnson, D.I. 1999. The guanine-nucleotide-exchange factor $\mathrm{Cdc} 24 \mathrm{p}$ is targeted to the nucleus and polarized growth sites. Curr. Biol. 9: 1183-1186.

Turner, C.E. 2000. Paxillin and focal adhesion signalling. Nat. Cell Biol. 2: E231-E236.

Turner, C.E., Brown, M.C., Perrotta, J.A., Riedy, M.C., Nikolopoulos, S.N., McDonald, A.R., Bagrodia, S., Thomas, S., and Leventhal, P.S. 1999. Paxillin LD4 motif binds PAK and PIX through a novel $95-\mathrm{kD}$ ankyrin repeat, ARF-GAP protein: A role in cytoskeletal remodeling. J. Cell Biol. 145: 851-863.

Tyers, M. and Jorgensen, P. 2000. Proteolysis and the cell cycle: With this RING I do thee destroy. Curr. Opin. Genet. Dev. 10: $54-64$.

Van Aelst, L. and D'Souza-Schorey, C. 1997. Rho GTPases and signaling networks. Genes \& Dev. 11: 2295-2322. 
Weiner, O.D., Servant, G., Parent, C.A., Devreotes, P.N., and Bourne, H.R. 2000. Cell polarity in response to chemoattractants. In Frontiers in molecular biology: Cell polarity (ed. D.G. Drubin), pp. 201-239. Oxford University Press, Oxford.

Whitehead, I.P., Campbell, S., Rossman, K.L., and Der, C.J. 1997. Dbl family proteins. Biochim. Biophys. Acta 1332: F1F23.

Yu, F., Morin, X., Cai, Y., Yang, X., and Chia, W. 2000. Analysis of partner of inscutable, a novel player of Drosophila asymmetric divisions, reveals two distinct steps in inscutable apical localization. Cell 18: 399-409.

Zahner, J.E., Harkins, H.A., and Pringle, J.R. 1996. Genetic analysis of the bipolar pattern of bud site selection in the yeast Saccharomyces cerevisiae. Mol. Cell. Biol. 16: 18571870.

Zheng, Y., Bender, A., and Cerione, R.A. 1995. Interactions among proteins involved in bud-site selection and bud-site assembly in Saccharomyces cerevisiae. I. Biol. Chem. 270: 626-630. 


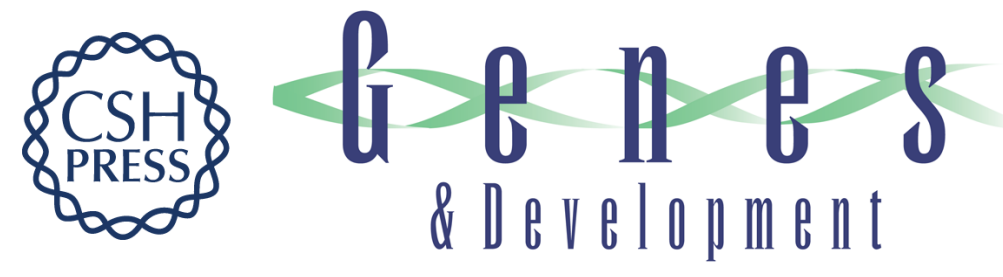

\section{Temporal and spatial regulation of Rho-type guanine-nucleotide exchange factors: the yeast perspective}

Marie-Pierre Gulli and Matthias Peter

Genes Dev. 2001, 15:

Access the most recent version at doi:10.1101/gad.876901

References This article cites 107 articles, 53 of which can be accessed free at: http://genesdev.cshlp.org/content/15/4/365.full.html\#ref-list-1

License

Email Alerting

Receive free email alerts when new articles cite this article - sign up in the box at the top Service right corner of the article or click here.

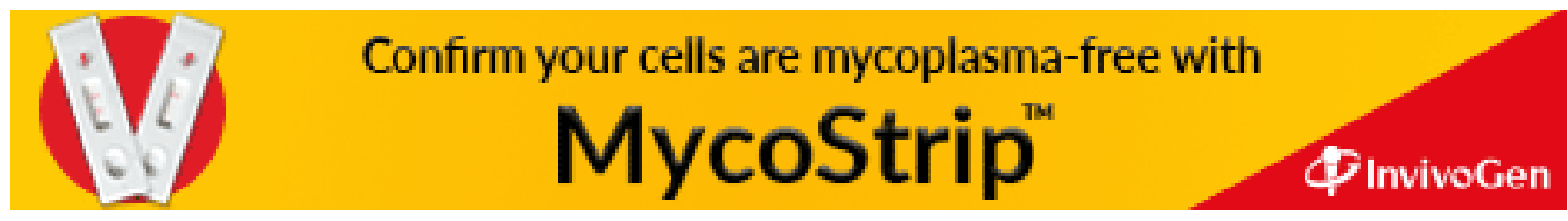

